\title{
PIERWSZY INWENTARZ KSIĄG KLASZTORU CYSTERSÓW W SZCZYRZYCU SPORZĄDZONY ZA RZĄDÓW PROFESA PELPLIŃSKIEGO A NASTĘPNIE OPATA W SZCZYRZYCU FLORIANA ANDRZEJA GOTARTOWSKIEGO (1753-1766)
}

\section{Krótki zarys rządów Andrzeja Floriana Gotartowskiego w Szczyrzycu}

Po śmierci opata Franciszka Gerarda de Hirtenberg Pastoriusza, która nastapiła 14 IX 1752 r. kolejnym opatem klasztoru szczyrzyckiego został Florian Andrzej Gotartowski, profes pelpliński, wybrany przez kapitułę klasztorną w Szczyrzycu 4 V 1753 r., pod przewodnictwem Wikariusza Generalnego Polskiej Prowincji Cystersów i opata pelplińskiego, Hieronima Turno ${ }^{1}$. Benedykcję opacką otrzymał Gotartowski 20 VIII 1753 r. z rąk biskupa chełmińskiego, Stanisława Leskiego, zaś na urząd opacki instalowany został w Szczyrzycu 13 X 1753 r. przez opata jędrzejowskiego, Wojciecha Ziemnickiego (...) 4ta Maji Secretario Provinciae Antistites electus, sub praesidentia Rmi D. Hieronymi Turno Abbatis Pelplinensis Provinciae Polonae Commissari Vicary Generalis ab Ilustrissimo ac Rmo Dno Stanislao Leski Episcopo Culmensi 20 Augusti Pelplini benedictus; a Rmo D. Adalberto Ziemicki Claustrali Abbate Andreoviensi 13 Octobris ad sedem Abbatialem Ciricensem instalatus est (... $)^{2}$.

Opat Florian Andrzej Gotartowski pochodził z Prus, choć nie dochowały się dokładniejsze opisy miejsca jego urodzin, wiadomo, że jego rodzicami byli Andrzej i Anna. Gotartowscy pieczętowali się herbem „Leliwa” (...) Hic in baptismate Andreas nominatus claris natalibus in Prussia Andrea et Anna parentibus Anno 1723 ortus, Gedani humanitoribus studiis ex cultus religionem cisterciensem in

* Jolanta M. Marszalska - dr hab. nauk humanistycznych, adiunkt w Instytucie Nauk Historycznych UKSW w Warszawie.

${ }^{1}$ J. M. Marszalska, W. Graczyk, Opaci i przeorzy klasztoru oo. Cystersów w Szczyrzycu od XIII do XX wieku, Tyniec 2006, s. 163.

${ }^{2}$ Archiwum i Biblioteka Klasztoru Cystersów w Szczyrzycu (dalej: Arch. i BOcist.), Servitus Sancta [...] descriptus 1751, s. 38, [b. sygn]; T. Magiera, Series Antistitum Monasterii Szczyrzyc [...], w: Xenia Bernardina, t. 3, Wien 1891, s. 322. 
Monasterio Pelplinensi sub Reverendo Anno Adalberto Stanislao Leski Abbate praedicti Monasteri 1739 prpfessus, subdiaconus a reverendo Michaele Kunicki episcopi Arsionensi, sufraganeo cracoviensis. Diaconus ab Illustrissmo ac Reverendissimo Domino Valentino Czapski episcopo Vladislaviensi, quondam Abbade Pelplinensi factus tandem ab Illustrissmo ac Reverendissimo Domino Adalberto Stanislao Leski similiter ex Abbate Pelplinensi episcopo p. t. Culmensi 1748 presbiter ordinatus est (... $)^{3}$. Opat Gotartowski, pochodzący z odległych od Małopolski Prus, i zapewne stykający się $\mathrm{w}$ ciagu swego zakonnego życia $\mathrm{z}$ nieco inną rzeczywistością i realiami, jakie bez wątpienia widoczne były między pomorskim opactwem w Pelplinie i jednym z najmniejszych opactw na ziemiach polskich Szczyrzycem, zapisał - co warto podkreślić - ważną kartę w dziejach tego ostatniego. Wzorem swoich poprzedników na urzędzie opata w Szczyrzycu okazał się godnym kontynuatorem prac remontowo-budowlanych podjętych jeszcze za opata Franciszka de Hirtenberg Pastoriusza. W 1761 r. na polecenie Gotartowskiego rozebrano starą bramę opacką a na jej miejscu ustawiono monumentalną bramę z kamienia ciosanego, zwieńczoną posagami Wniebowzięcia Matki Bożej, św. Stanisława Biskupa, oraz św. Bernarda z Clairvaux, którą na polecenie opata wykonał mistrz kamieniarski, Wojciech Łuczyński. Zlecono także wykonanie gradusów przed bramą ,,(...) tu przedtem żadnego nie było, ziemia tylko nierówna kamieniami głazowemi wyłożona. Ojciec Przeor ziemię kazał wyrównać, dlatego że wysoko było do babieńca wstępować, zaczym trzy gradusy ułożone, z tych gradusów, które były w kościele między chórami ojcowskimi"4. Zrobiono też schody przed nową bramą, wykorzystując budulec ze stopni znajdujących się dotychczas we wnętrzu kościoła, w chórze zakonnym. Na zachód od tej bramy w latach 17601761 założono cmentarz zakonny, zlokalizowany w miejscu obecnego ronda; do tego czasu zakonników grzebano głównie w krypcie pod północną kaplicą kościoła (...) Przed cmentarzem przy klasztorze szczyrzyckim WW. OO. Cystersów sumptem i kosztem Communitalis roku 1761 zaczęta i dokończona za przetożeństwa Bernarda Reydlewicza, profesa paradyskiego, przeora na ten czas konwentu szczyrzyckiego (...). Cmentarz ten klasztorny i z dali ku browarowi śliwami byt zasadzony, przy drzwiach samych kościelnych wielki byt orzech włoski, który podczas straszliwej bardzo mroźnej i dtugiej zimy w roku 1739 usecht, dla mizerij ostatniej w konwencie nie przyszło do tego aby byt honeste optakniony, zaczym jak mogło być przy biedzie, jak tak byt zastraszony deskami az dopiero po śmierci Jmci Romiszowskiego opata (jak mówiq mors Abbatum gaudium Monachorum), klasztor sie posilit i do grosza przyszedl, za czym brat Alberyk prowizor $w$ roku 1729 bramke drewniana przy cmentarzu a nad bramka izdebke, przy tej izbie, izbe z komnata dla gości, przy tej spichlerz dalej wozownia, dalej stajnie bez ksztattu i proporcji swoimi prostaczkami poddanemi wystawit, które klatki przez lat 31

\footnotetext{
${ }^{3}$ Servitus Sancta, s. 38.
}

${ }^{4}$ Arch. i BOCist. Kontrakt opata Pastoriusza z mistrzem kamieniarskim Wojciechem Łuczyńskim, sygn. XXI. 312; Inventarium Cirzickiego Kościoła [...] 1727, [b. sygn.], k. 11-11v; E. Łużyniecka, J. M. Marszalska, Szczyrzyc, s. 113. 
staty, aże tandem W.O. Reydlewicz przeor tw klatki jako już poruinować zburzyt teraz nastepuje erekcja bramy.

W zachowanych zapisach kronikarskich klasztoru szczyrzyckiego, znajdujemy jeszcze kilka informacji o podejmowanych przez Gotartowskiego inicjatywach remontowo-budowlanych obiektu klasztornego, czy też sporach jakie toczył opat między innymi z dominikanami jodłownickimi konwentu św. Trójcy w Krakowie w sprawie kradzieży drzewa i innych krzywd jakie wyrządzali dominikanie w dobrach konwentu szczyrzyckiego , [...] ad malum proclivorum ubi cavendum et timeridum est ne et ceteri in ibidem malitiori homines tantorum clausuum et vilentiarum spectatores $[. . .]^{\prime \prime}$. Nie brakowało też problemów „natury dobrego sąsiedztwa" tym razem z karmelitami bosymi z Wiśnicza, które z małymi przerwami ciagnęły się od 1684 r. Dbałość i troska o klasztor szczyrzycki nie ograniczała się jedynie do przedsięwzięć natury gospodarczej czy budowlanej, była to również troska o otoczenie klasztoru i jego dobra. Warto tu wspomnieć, że opat Gotartowski za swoich rządów zatrudnił ogrodnika, który za odpowiednim wynarodzeniem miał założyć ogród w Krzyszkowicach, należących do dóbr opackich i utrzymać go w należytym poziomie (...) Kontraktem niniejszym przyją u nas stużbe stawetny Marcin Miller profesyi ogrodnik na trzy lata, to jest od S. Jana Roku 1759 aż do Roku 1762 (...) ogród w Krzyszkowicach, dobrach naszych opackich nowo należycie zatożyć i doskonale wedtug podanego obrysu wyreterutować, tak wyższa jak też i niższa kondygnacyje a co by w tych trzech leciech do zupetnej nie przyszło doskonatości, tedy i dlużej przy tymże ogrodzie krzyszkowskim zostawać na ustugach naszych obliguje się biorac na się wszelkie powinności onym ogrodowym zwykte (...). Wedtug zaś ugody wzajemnej się naznacza na każdy rok ordynaryi piwa beczek 6, żyta korcy czyrzyckich 8, pszenicy korcy czyrzyckich4, jeczmienia korcy czyrzyckich 4, grochu korcy czyrzyckich korcy dwa $(\ldots)^{7}$. Dbałość o klasztor przejawiała się również w aktywności opata na płaszczyźnie duchowej, co z kolei przekładało się w ilości składanych profesji. I tak za 13 - letnich rządów opata Floriana Andrzeja Gotartowskiego w Szczyrzycu, złożyli profesję zakonną następujący zakonnicy: Florianus - laicus w 1753 r., Gregorius - laicus w 1755 r., Ambrosius - laicus w 1755 r., Augustinus Stypa - laicus w 1756 r., Hieronymus Gieczy - laicus w 1758 r., Valentinus Janikowski - laicus W 1766 r. $^{8}$

Równie ważnym wyznacznikiem rządów opackich było właściwe podzielenie funkcji wśród zakonników konwentu szczyrzyckiego. Daje ono obraz, kto, kiedy i jaką sprawował funkcję i za co był odpowiedzialny. I tak urząd przeora pełnili: w 1755 roku - Bernard Zaleski ${ }^{9}$, w 1760 - Bernard Reydlewicz, w 1762 - Kilian Kriger; podprzeora: w 1755 roku - Mikołaj Rybczyński, w w 1760 roku

${ }^{5}$ Inventarium Cirzickiego Kościoła, k. 10.

${ }^{6}$ Arch. i BOCist. sygn. I. 4.

${ }^{7}$ Arch. i BOCist. Kontrakt opata Gotartowskiego z ogrodnikiem Marcinem Millerem, sygn. XXI. 308.

${ }^{8}$ Servitus Sancta, s. 39-42.

${ }^{9}$ Arch. i BOCist. sygn. I. 4; sygn. III. 22; sygn. V. 20; sygn. V. 30; sygn. V. 35; sygn. V. 201; sygn. V. 224; sygn. V. 226; sygn. VI. 116; sygn. VIII. 110; sygn. VIII. 112; sygn. XXI. 159/e; sygn. 
- Rajmund Gurczyński; prowizora: w latach 1755-1765 - Andrzej Krepczyński ${ }^{10}$, w 1762 roku - Hieronim Gieczy ${ }^{11}$; bibliotekarza: w 1762 - Florian Gałbiński; kaznodziei i magistra nowicjatu - w 1765 roku - Mateusz Stachowski; magistra capellae: w 1765 roku - Wojciech Lisner; organariusa: w 1765 roku - Jan Kalinkowski; szewca: w 1765 - Alan Rezengal; kapelana opata: w 1765 roku - Augustyn Stypa. Oprócz nich w klasztorze byli obecni: Antoni Stawski, Józef Siewert, Jan Kanty Piastuszyński, Franciszek Wenecki, Niward Dochodnicki, Grzegorz Gozdalski, Ambroży Guzikowski, Benedykt Hoffman, Walenty Janikowski, Grzegorz Garoselski, Stanisław Komierowski - proboszcz w Ludźmierzu, Antoni Brzyski z Koprzywnicy ${ }^{12}$.

Pod koniec rządów opata Floriana Andrzeja Gotartowskiego w Szczyrzycu, kroniki odnotowały tragiczny w swych skutkach pożar, który w $1765 \mathrm{r}$. wybuch w klasztorze. W czasie pożaru spłonęła najpierw stajnia gościnna, później karczma kryta strzechą i młyn. Następnie ogień przeniósł się na dach refektarza, altanę w ogrodzie, oraz kościół. Spłonęły drewniane wieże zachodnie i sygnaturka z zegarem kurantowym. Później ogień zaatakował niesklepione izby opackie i skrzydło wschodnie klauzury, doszczętnie spłonęły niedawno wykonane dachy skrzydła zachodniego. Pożogę przetrwały mury i sklepienia kościoła, wielki ołtarz i organy kościelne; małe ołtarze wyniesiono przed kościół. Ocalały także sklepione pomieszczenia biblioteki i pięć cel dormitorium z podłogami w postaci grubej warstwy polepy oraz brama opacka, spichlerz, browar, stajnie i zabudowania gospodarcze ${ }^{13}$. Wkrótce po tym tragicznym zdarzeniu opat Gotartowski przeniósł się w 1766 r. do Pelplina, gdzie po śmierci opata Mikołaja Turno w 1767 r.objął rządy opackie w tamtejszym klasztorze ${ }^{14}$.

\section{Inwentarz księgozbioru klasztornego z 1755 r. i pomieszczenia do przechowywania ksiąg}

Należy podkreślić, iż pierwszy zachowany w klasztorze szczyrzyckim Inwentarz ksiag biblioteki klasztornej (zachował się do naszych czasów zaledwie jego niewielki fragment), to bez wattpienia zasługa opata Floriana Andrzeja Gotartowskiego. Dokładna charakterystyka Inwentarza z 1755 r. nie jest możliwa. Wiadomo, że do czasów nam współczesnych zachowały się tylko dwie jego początkowe karty, obejmujące spis ksiag w obrębie litery A.

Inwentarz został sporządzony na papierze czerpanym. Tekst na dwóch ocalałych kartkach jest pisany jednej ręki, na co wskazuje identyczny dukt pisma, w wielu miejscach niestaranny. Karty podzielono na rubryki w sposób następujący: sze-

XXIII. 9; sygn. XXIII. 12; sygn. XXIII. 15. sygn. XXIV. 120; B. Reydlewicz, Provisio [...], sygn. 754, s. 123, 125, 285, 288.

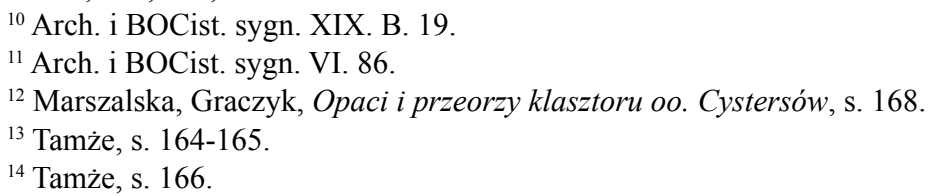


roką, środkową kolumnę przeznaczono na wpisanie nazwiska autora i tytułu dzieła, wąską kolumnę po prawej stronie karty na oznaczenie formatu dzieła. Nie było osobnej kolumny na oznaczenie miejsca i roku wydania w przypadku dzieł drukowanych. W obrębie litery A, opisywane księgi, bądź ich autorzy nie byli ujęci w dokładnym porządku alfabetycznym. Inwentarz rozpoczyna Ariosto Alexander ze swoim dziełem Enchiridion. Kilka linijek poniżej został zapisany Alciatus oraz Acta Synodu gnieźnieńskiego itd. W spisie nie zastosowano osobnego wydzielenia formatów. Formaty in folio, in quarto, in octavo i in duodecimo zostały przemieszane ${ }^{15}$.

Opis bibliograficzny poszczególnych dzieł nie prezentuje wysokiego poziomu umiejętności bibliotekarskich. Jest to zresztą zjawisko charakterystyczne dla wielu klasztornych opisów inwentarzowych z XVIII w. Jak już zaznaczono, opis jest lakoniczny, ograniczony do podania imienia i nazwiska autora oraz kilku wyrazów tytułu. Tytuły są skracane według własnych ustaleń bibliotekarza klasztornego(np.Paradoxa, Abecadarium liber, Axiomatachrześcijańskiejfilozofii). W przypadku dzieł tego samego autora, tylko przy pierwszej pozycji zostało umieszczone nazwisko, bądź tytuł dzieła, kolejne zaś tytuły zastappiono słowem ejusdem. Zasadniczo Inwentarz spisywany był w języku łacińskim. Tylko Summariusz osób Światobliwych Zakonu O.S. Benedykta X. Wegrzynowicza - zapisano w języku polskim. Przy żadnym z opisywanych dzieł nie podano miejsca, roku wydania ani oficyny wydawniczej. $Z$ elementów opisu zewnętrznego bibliotekarz klasztorny nie podaje żadnych szczegółów, oprócz formatu książki. Nigdzie nie podano też sygnatury miejsca. Na podstawie zachowanych kart Inwentarza trudno ustalić jaki schemat zastosowano do opisu całego księgozbioru. Można jedynie sądzić, że zbiór ksiąg był prawdopodobnie ułożony według alfabetu, bez wyszczególnienia działów grupujacych zgromadzone piśmiennictwo. Zachowane dwie karty obejmują łącznie 46 ksiąg, nie mogą więc z oczywistych względów być reprezentatywne dla określenia zasobności biblioteki szczyrzyckiej w pierwszej połowie XVIII w. Powyższe stwierdzenie odnieść również można do metody sporządzenia Inwentarza, jakkolwiek ta jest już bardziej czytelna. Pozwala to przypuszczać, że pozostały księgozbiór również spisano według zastosowanej wcześniej zasady, widocznej na zachowanych dwóch kartach Inwentarza.

Warto zaznaczyć, że w ocalałym fragmencie znajdujemy między innymi dzieła wybitnego teologa i filozofa średniowiecza, św. Alberta Wielkiego, mistrza i nauczyciela św. Tomasza z Akwinu, Philosophia de anima [Wenecja, 1481] oraz De natura et immortalitate animae [Norymberga, 1493] - zachowane do dnia dzisiejszego. Oba były przedmiotem studiów o czym świadczy na wielu kartach zachowana glosa marginalna, a także dzieło słynnego dominikanina, Antoniego

${ }^{15}$ Prawdopodobnie zamierzeniem spisującego było stworzenie katalogu biblioteki, a nie inwentarza co często bywa utożsamiane, zasadnicza cecha, która odróżnia katalog od inwentarza tkwi w odmiennych zadaniach obu spisów. Katalog służy do udostępnienia księgozbioru, wskazuje przy tym miejsce przechowywania określonego tytułu; inwentarz ma na celu przede wszystkim ustalenie stanu majątkowego danej instytucji w zakresie posiadanych przez nią zbiorów. Por. J. Grycz, Bibliotekarstwo praktyczne, Warszawa 1945, s. 71; A. Więckowska, H. Pliszczyńska, Podręczny stownik bibliotekarza, Warszawa 1955, s. 88. 
z Florencji Confessionale z traktatu Sermo de poenitentia, Jana Chryzostoma [Strassburg, non post 1484]. Confessionale posiada wpis własnościowy opata szczyrzyckiego, Piotra Borowskiego. Wyżej wymienione dzieła szczęśliwie przetrwały do dnia dzisiejszego i znajdują się w księgozbiorze klasztornym. Wprawdzie nie zachowały się do chwili obecnej ale znajdowały się w połowie XVIII w. w zbiorach klasztornych, dzieła św. Augustyna: De doctrina Christiana, zamieszczone w Opuscula [Kraków, ca 1476], oraz Meditationes, zamieszczone również w Opuscula, lecz w znacznie późniejszym wydaniu [Wenecja, 1483]. Spośród późniejszych teologów reprezentowanych w Inwentarzu z 1755 r. na szczególną uwagę zasługują: De institutione grammatica libri tres, autorstwa Manuela Alvareza, portugalskiego jezuity, rektora Kolegium w Coimbrze i Evorze; dzieło $\mathrm{Me}$ dulla theologica, autorstwa Ludwika Abelly, jednego z pierwszych uczniów św. Wincentego a Paulo. Dzieło Medulla spełniało funkcję podręcznika teologii dogmatycznej; ponadto Orationes, Mikołaja Avancini, jezuity, pisarza i poety ascetycznego, wykładowcy retoryki i gramatyki w Trieście, Lublianie i Wiedniu a także Conciones, Józefa Acosty, hiszpańskiego jezuity, pisarza i misjologa. Warto zaznaczyć, że ten ostatni prowadził działalność misyjną wśród Indian, która zaowocowała opracowaniem katechizmu w języku hiszpańskim i indiańskim: kiczua i ajmara. Dzieło to było instrukcją dla spowiedników Indian. Oprócz treści teologicznychi duszpasterskichautor zawarłwniminformacje etnograficzneoAmeryce, opisy jej świata mineralnego, roślinnego, zwierzęcego oraz przedstawił zasady moralności indiańskiej. Położył duże zasługi w rozwoju wiedzy o życiu i zwyczajach Indian, dzięki czemu nazywany był Pliniuszem Nowego Świata ${ }^{16}$.

$\mathrm{Z}$ autorów polskich odnotowano $\mathrm{w}$ omawianym fragmencie Inwentarza, obecność Arnolfa Żeglickiego, pijara, moralisty, rektora Kolegiów pijarskich w Chelmie, Podolińcu i Warszawie, dziełem Adagia polonica... [Warszawa, 1751].

Zachowane zaledwie dwie karty Inwentarza ksiąg w obrębie litery „A”, sporządzonego za czasów opata Gotartowskiego zawierają dzieła wybitnych teologów i filozofów, którzy odcisnęli niezatarte piętno w kształtowaniu świadomości chrześcijańskiej minionych wieków.

Godnym podkreślenia jest również fakt, iż w czasach rządów opata Gotartowskiego, księgi przechowywane były w specjalnie przeznaczonym do tego celu pomieszczeniu. Wynika to $\mathrm{z}$ opisu pożaru klasztoru odnotowanego $\mathrm{w}$ kronice, zwanej potocznie Revisio. Pożar ten miał miejsce w 1765 r. pod koniec rządów opata Andrzeja Floriana Gotartowskiego ${ }^{17}$. Od opackich izb poszedt ogień na dachy dormitarskie od wschodu. Biblioteka przecie i sklepik przy niej, w którym monimenta wszystkich zapisów, cudem boskim wewnatrz nie zgorzały, naprzód, że sklepione były, do tego, że okna z zewnatrz byty, któremi wiatr płomienie zawinać nie móg $t^{18}$. W czasie pożaru spłonęły drewniane wieże zachodnie i sygnaturka z ze-

${ }^{16}$ M. Jagusz, Acosta Jose de (1540-1600), w: Encyklopedia Katolicka, t. 1, red. F. Gryglewicz, Lublin 1973, kol. 60.

${ }^{17}$ Łużyniecka, Marszalska, Szczyrzyc, s. 57, 115; Marszalska, Graczyk, Opaci i przeorzy klasztoru oo. Cystersów, s. 164-166.

${ }^{18}$ Arch. i BOcist. Revisio Praediorum, Inventariorum, Subditorum, ac omnis suppellectillis ad Oeconomiam pertinentium ...Villis Monasterij Ciricen.S.O.Cist. ... Anno 1741, k. 15-16v; sygn. S.V. 
garem kurantowym. Doszczętnie spaliły się dachy skrzydła zachodniego. Pożogę przetrwały mury i sklepienia kościoła, wielki ołtarz i organy kościelne. Ocalały także sklepione pomieszczenia biblioteki i pięć cel dormitorium ${ }^{19}$. Z zapisu jasno wynika, iż biblioteka usytuowana była na piętrze od strony wschodniej, tuż nad zakrystią kościoła. O jej wyposażeniu nie zachowały się z tego okresu żadne dane źródłowe.

Zachowany fragment pierwszego Inwentarza ksiąg świadczy bez wątpienia o podejmowaniu przez opata Floriana Andrzeja Gotartowskiego starań około spisania i uporządkowania książek. Jak wynika to z analizy zachowanych kart był on sporządzony alfabetycznie. Bez wattpienia nawet ten niewieli zachowany fragment stanowi ważne źródło historyczne do poznania kultury intelektualnej i duchowej konwentu szczyrzyckiego. Pozwala w sposób, co prawda niedoskonały odtworzyć stan ksiagozbioru, jego zawartość treściowa, autorów dzieł, oraz poznać miejsce i oficyny wydawnicze z których księgi pochodziły.

\section{DAS ERSTE INVENTARVERZEICHNIS DER BÜCHER DES ZISTERZIENSERKLOSTERS IN SZCZYRZYC, ERSTELLT WÄHREND DER AMTSZEIT DES PELPLINER PROFESSORS UND SPÄTEREN ABTES IN SZCZYRZYC FLORIAN ANDRZEJ GOTARTOWSKI (1753-1766)}

\section{Zusammenfassung}

Am 4. Mai 1753 wählte das Szczyrzycer Kapitel auf seiner vom Generalvikar der Polnischen Provinz und Abt von Pelplin Hieronim Turno geleiteten Sitzung den Pelpliner Profess Florian Andrzej Gotartowski, Wappen Leliwa, zum neuen Abt von Szczyrzyc. Nach dem Vorbild seiner Vorgänger im Amt des Abtes von Szczyrzyc erwies er sich als würdiger Fortführer der noch unter dem Abt Franciszek de Hirtenberg Pastoriusz begonnenen Renovierungs- und Bauarbeiten. Ein Ausdruck seiner Sorge für die Klosterbibliothek war, dass Abt Gotartowski die Anweisung erteilte, die Bücherbestände zu notieren. Schade, dass bis in unsere Zeit nur ein Fragment des damals erstellten „Cathalogus librorum Monasterii Ciricensis iuxta alphabetum authorum mense Augusto Anno Domini 1755 " erhalten geblieben ist. Es muss hervorgehoben werden, dass die erhaltenen zwei Blätter des in der Amtszeit von Abt Gotartowski erstellten Bücherverzeichnisses im Rahmen des Buchstabens „A” die Werke hervorragender Theologen und Philosophen enthalten, die die Gestaltung des christlichen Bewusstseins der vergangenen Jahrhunderte unauslöschlich geprägt haben.

Aus dem Polnischen übersetzt von Herbert Ulrich

10; nr inw. 692; J. M. Marszalska, Najważniejsze źródła rękopiśmienne do dziejów klasztoru oo. Cystersów w Szczyrzycu, „Nasza Przeszłość”, 104 (2005) s. 62-64; Marszalska, Graczyk, Opaci i przeorzy klasztoru oo. Cystersów, s. 164-166.

${ }^{19}$ Łużyniecka, Marszalska, Szczyrzyc, s. 57. 